\title{
Learning from Aviation. Learning from Architecture. Or Cockpits and Hospitals Psychologically Considered, from Arnheim to Barshi
}

\author{
JOY KNOBLAUCH \\ University of Michigan
}

This paper begins with the deceptively simple question of what architecture can learn from aviation psychology and what aviation psychology can learn from architectural design. In the process, I hope to explore new ways for research to "articulate architecture's disciplinary core while contributing to its evolution." The experience of flying a plane and the aviation industry's adaptation to that affective condition of sensory intensity, high emotional stakes, and also boredom / monitoring provide an example that is both similar and different from the artistic modes that have informed the last fifteen years of design's interest in gesture, empathy, and affect. Brian Massumi and others have looked to film and design pedagogy for lessons about the mutual interplay of emotional and intellectual processing. Historian Zeynep Çelik Alexander has posed a provocative question of what modern design might be or have been if the affective component were returned to it. John Harwood, Brandon Hookway, and many others have posed design as essentially the construction of interfaces that reduce the pain of the engagements of subject and machine that capitalism of the late 20th century seemed to require. My own previous work in the history of architecture and its engagement with psychology in institutional design leaves me unsure about the advantage of asking folks to talk about what they seek or how they perceive highly emotional environments such as hospitals. Instead, might design observe more directly the ways intensity and content interact and amplify, as Massumi has suggested? How can we learn from cockpits and hospitals to produce a more critical physical and mental ergonomics?

\section{INTRODUCTION}

This year's ACSA conference takes up the idea of treating the discipline of architecture as a black box to be known only by its outputs as explored in an essay by Reyner Banham.1 If architects were to set aside many of the internal debates about form and history, how might the discipline be evaluated by what it can do? If the work of behavioral psychologists such as B.F. Skinner are any guide, architects would find a field somewhat impoverished in explanation but improved in their ability to manipulate behavior through environment. The black box of course has another meaning, also as a reduced form of information when it refers to the object that records data and the sounds of the cockpit. This black box, like the other, is a technology for reduction but retention of essential information. For my contribution to the shared thought experiment about architecture's disciplinarity as a black box, I want to argue for the contents of that box but I also want to have a conversation about the limits of those contents.
This paper will compare architecture and aviation, retaining each discipline as an entity with its own core problems and useful methods. Through juxtaposition it becomes clear that at the core of each field is a shared need to know about the psychology of occupying space. Both fields are concerned with spaces where intense sensory experience occurs in environments that are highly permeated with technological interfaces and wherein human subjects experience threats to continued life. The cockpit and the hospital will form the core site of comparison, not only because it has been argued by others that these places have shaped conceptions of architecture as "functional" or "modern" rather than as places to sustain a fully human experience. The histories of aviation and architecture show that these spaces of violence and machine have been highly-regulated by government and have often been the beneficiaries of extensive military-funded psychological research.

Given that history of violence and military influence, it may be surprising that what comes to light in comparison of aviation with architecture is the role of emotion. The main argument of this paper is that theories of affect / sensory processing and their relation to meaning point to a way out of the blind alley that architecture has found itself in when it has tried to confront the psyche. I argue elsewhere that environmental psychology has been inadequate for architecture because it has been too oriented toward an outcome, too functionalist. It has often concerned itself with causing behavior or emotion in subjects and even more frequently it has been called on to perform acts of pacification or entertainment. On the other hand, phenomenology has struggled with solidarity and acceptance in search of a core explanatory base that could unite those with very different experiences and ways of interpreting the world. Theories of affect can suggest a way out of that impasse.

Aviation has already influenced architecture and this essay is likely just another moment of overlap. Historians, theorists, and architects have been interested in flight for roughly a hundred years. Allegedly the experience of flight--as the view from above--influenced Le Corbusier to conceive of design in a new way following his experiences in South America in 1928. ${ }^{2}$ In his book Aircraft, he explored the euphoria, the politics, and the formal properties of aircraft. Enrique Ramirez has written of the ways that theories of modernity have been shaped by laws and experiences of flight in France. ${ }^{2}$ Many architects have been interested in being pilots, and their methods of design have been compared to flying. ${ }^{3}$ Gyroscopic Horizons reveals Neil M Denari's interest in airplanes for their 


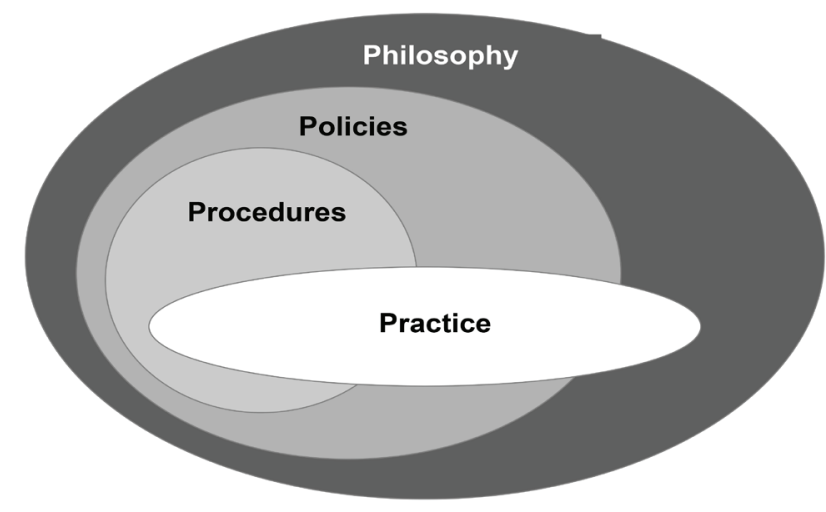

Figure 1. Immanuel Barshi Panel on "Pathways to Human-Centered Operating Principles" in "Trained for Life: Human-Centered Approach to Safety," Air Line Pilots Association Human Factors conference, May 31, 2018.

construction and for means of visualizing complex forms. ${ }^{4}$ And scholars such as Brandon Hookway and Peter Galison have noticed the importance of cockpits as models of the human machine interaction that one can safely say is now ubiquitous. ${ }^{5}$ And yet the discussion of flight and architecture could benefit from a greater understanding of emotion, so often clipped from these militarized ways of knowing.

\section{THEORY OF AFFECT}

In 1995, Brian Massumi published a classic essay about a set of experiments with children watching a story of a snowman melting. The program had frightened many of the children who had viewed it, leading a researcher named Hertha Sturm to evaluate various versions of the film to understand why. Sturm tested the children's response to three versions of the film: one was wordless, one had a basic narrative, and a third had an emotional narrative. The children reported that the wordless version was the most pleasant and the factual one was the least pleasant. The version with the factual narrative was also least remembered. By contrast, the emotional narrative was seen as somewhat pleasant and it was the most remembered. Looking back at this study, Massumi wondered about why the children reported the sad scenes as the most pleasant, and theorized that what truly mattered was arousal and not the content. The factual version, he theorized, had dampened arousal and produced the least pleasure no matter the content. The application of reason then, produced a decrease of emotion as well as a tendency to forget. ${ }^{7}$

What Massumi argued was that in the first half second of a sensory experience, the subject perceives the film as pure intensity, measurable as Sturm did via physiological means such as galvanic skin response. It is only later that cerebral processes attach meaning to the experience through language and other interpretations and representations. In other words, matter of factness dampens intensity (perhaps also in the case of the clipped, abbreviated speech of the radio in aviation and possibly other social formalities such as rules for nonviolent communication and many remedies for children's tantrums). Or, as Massumi writes:

Intensity is qualifiable as an emotional state, and that state is static--temporal and narrative noise. It's a temporal sink, a hole in time, as we conceive of it and narrativize it. It is not exactly passivity, because it is filled with motion, vibratory motion, resonation. And it is not yet activity, because the motion is not of the kind that can be directed (if only symbolically) toward practical ends in a world of constituted objects and aims (if only on screen).

\section{-Brian Massumi, "The Autonomy of Affect"}

The detachment of these processes from sensory experience may be surprising to those educated in architectural theories of social construction and post-structuralism, and it has been critiqued by some social psychologists for this reason. Yet the idea of a detachment between sense and meaning opens new understandings of the power of the interpretive lens placed over sensory experience. It also suggests that various sensory processing experiences perhaps grouped with neurodiversity have profound aesthetic implications.

Historians have started to look at the ways vision and other senses are socially-constructed and to ask if modern aesthetics was shaped by a particular mode of sensory reception and whether it has been exclusive of neurodiversity. Zeynep Çelik Alexander has uncovered a lost history of modernism that did take into account kinaesthetic forms of aesthetic response also known as Anschauung. She asks whether modernism went awry in its understanding of perception when it chose to follow Sigmund Freud's cerebral approach in Entwurfeiner Psychologie in $1895 .{ }^{9}$ She points to the value of elements that were retained a while longer, such as the comparative vision of Wöfflin or the movement studies of Hans Kessler and others at the Bauhaus in the 1930s. Caroline A Jones' book Sensorium links Clement Greenberg's conceptions of medium to a bourgeois desire to compartmentalize the senses to avoid the overstimulation of consumer culture. With the kinaesthetic and intellectual forms of reception out of balance, modernism may have missed avenues of exploration to which the discipline is only lately returning. What would it mean to reincorporate a nonrepresentational essence to architecture? What does aviation psychology already know about ways of switching between kinaesthetic knowing and the apparatus of representation?

\section{AFFECT IN FLIGHT}

The experience of flying an airplane is very high in intensity (in Massumi's terms) and possibly quite low in content. Unlike the experience of surgery or death, the experience of flight has little overt content. Flying may have numerous cultural 
implications, references, and artifacts but the experience tends to repel that meaning, rendering conversation distant as do many of life's experiences. With the added threat to one's survival (and possibly the 300 passengers of a commercial flight) a pilot engages with adrenaline and emotion in a particularly clear illustration of Massumi's theory. Decisions are made quickly, as can be the case for a designer under pressure or a human occupant who is navigating a hospital or other threatening space.

Sanford Kwinter has suggested that Rem Koolhaas designs in the manner of a World War II dogfight, unthinkingly testing the rules of form / flight, "If you have to think, you're dead." ${ }^{\prime 10}$ This type of thinking and of seeing quickly, known as tachyscopally, has been studied by art theorists and in aviation and leads researchers of human factors at NASA Ames to conclude that practice often exceeds both policy and procedure. ${ }^{11}$ (Figure 1) Architecture has also long understood the need to make very quick decisions, while embedded in larger networks of philosophy, policy, and procedure. Given the context of economic precarity that leads to scarcity of time, it is likely that Koolhaas is not the only architectural practice that feels like a dogfight.

To compensate for the impracticality of having the audience take controls of a plane to study affect with minimal context, representation will have to suffice. But I think the same point can be made through a sequence of film about Art Scholl, teacher, designer, and stunt pilot, made in 1968. Pilots (and film) have a means of articulating that which often exceeds language. ${ }^{12}$ After introducing Scholl as a fit and devoted scholar and pilot, the audience is shown footage of his acrobatic work where he narrates his process of thought while executing complex rolls and loops. (Figure 2)

I can feel it on the seat. Coming around.

Airspeed coming up on 190 again.

Vertical.

Half roll.

Stop.

Horizon looks good. Push over the top.

Altitude. Altitude. Good on the altitude, 1,000 feet.

Lean down.

Pushing forward. Pushing forward.

Watch the ground, watch the ground, Art. Okay looks good. Coming out. Right down the runway. Half roll. Out.

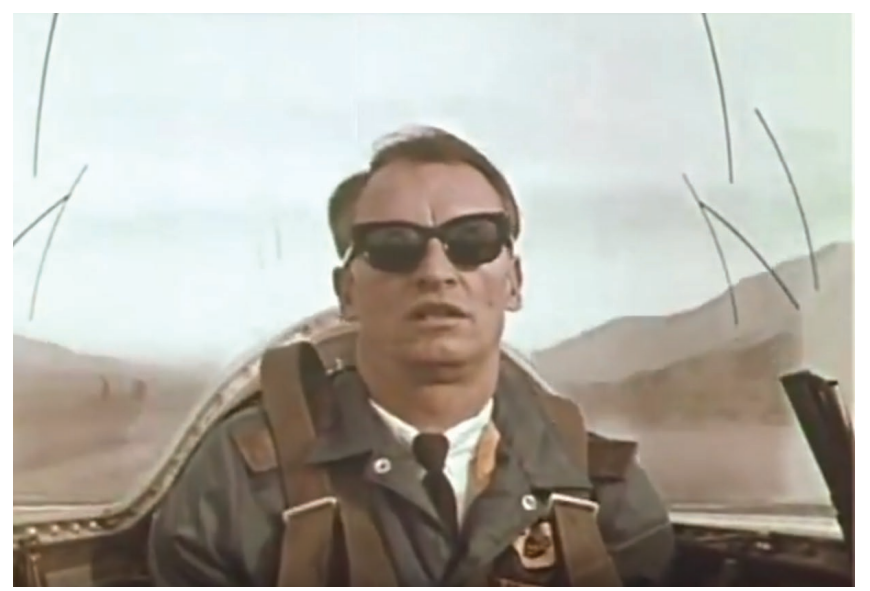

Figure 2. Film still from Bill Rice: "The Crowd Above Me, The Sky Below." (1968)

Scholl then describes his experience as a human whose appendages extend into a machine in a manner that presses the capacity of the human sensorium. He explains his experience as "Locked in as part of the airplane" or "A feeling that is just very difficult to explain." This experience has been called distal attribution and it may take a figure as experienced as Scholl (who you will recall was also a teacher) to be able to articulate his working process. Perhaps this narration is evidence of the elite level he reached and presumably he translated his nonrepresentational knowledge after landing the airplane. If there were more time, many questions about pedagogy could be discussed here.

The emotional impact of form has been a core disciplinary subject of conversation in architecture for over twenty years and lacks adequate resolution. A solid theory would be of use in the design of hospitals, prisons, mental health centers, housing, and other environments meant to soothe. The history of such attempts is of course hundreds of years long and of more recent interest after World War II as various government strategies have sought to use the environment as a means of population management. ${ }^{13}$ Design was of interest to hospital planners and public relations experts in the postwar as hospitals expanded and modernized in the United States ahead of demand after 1946. The public had concerns that were not so much about technology as about money and confinement. The United States Public Health Service issued a call to architects to get them involved in raising matching funds and encouraging them to design palatable institutions. Architects like Isadore Rosenfield and E Todd Wheeler considered the mentality of the patient. Rosenfield saw the building as a means of managing the emotions of both patients and staff and advocated an approach that "permits the "logic inherent in conditions, rather than emotions, to give shape and character to the hospital building." ${ }^{14}$ To communicate that "They should be made to feel that their friends or dear ones are in the presence of kindness, consideration, and scientific certainty." Such dampening of emotion via design 

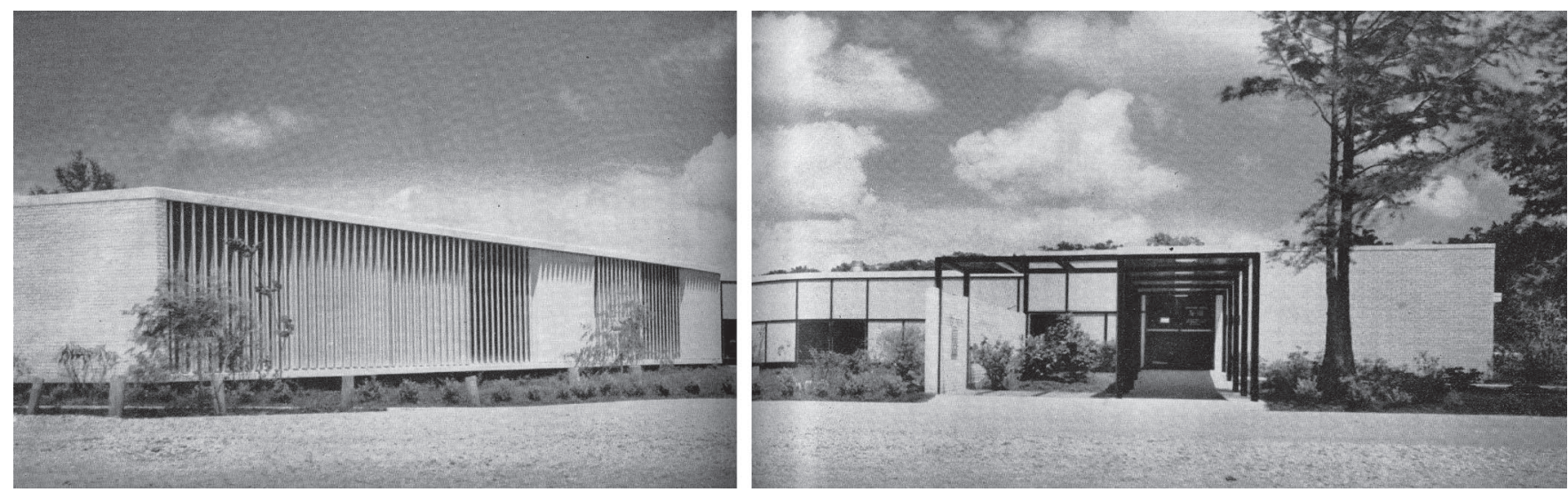

Figure 3. Lakewood Hospital, Morgan City, Louisiana by Curtis \& Davis attempts to be legible to the public through changes in the building's skin: "Exterior walls express different portions of the hospital: louvered nursing wing at left, paneled diagnostic core, with entrance and administration far right."Frank Lotz Miller, photographer, Morgan City, Louisiana, Architects: Curtis \& Davis, Hospital Consultant: Jesse Bankston, General Contractor: Caldwell \& McCann. "An Argument for the One Story Hospital", Architectural Forum, 1956, 119.

might be valuable or might be replaced with environments that do not alienate a patient or family from the experience. But how would that be done? (Figure 3)

\section{DESIGN MATTERS: WHAT AVIATION CAN LEARN FROM ARCHITECTURE}

The core of architecture as a discipline includes truths about the way form is perceived, notably in the tradition of formal analysis that grew out of the studies by Heinrich Wölfflin in the early twentieth-century that Çelik Alexander mentions and which lead forward through Colin Rowe's explorations of simultaneous perception in his collaboration with Robert Slutzky. ${ }^{15}$ Aviation has learned a lot about helping humans cope with an intense and high stakes environment, and yet some of those representational tools might well benefit from the expertise of design.

Aviation has needed to study the problem of accuracy amidst both intense emotional situations (particularly in wartime) and also long stretches of uneventful time. They have sought technical interfaces and patterns of communication as well as other simple tools that are more cultural. Such simple tools are already being adapted away from aviation, most famously in the case of Atul Gawande's checklist manifesto that adopted the procedure for doctors as a means of reducing errors. ${ }^{16}$ Pilots develop their own nomenclature and graphic notation suited to the particulars of their context and priorities. Pilots, healthcare workers, architects and many others find that it is not wealth of information but management of the flow that is the challenge.

Some of these exist in a barely designed state that could benefit from the interventions of those versed in composition of complexity, namely architects. Designers at STAMPS have taken on this question of designing a simpler paperwork version to prevent the burnout of Electronic Health Records. ${ }^{17}$ Architects as well find there are many things to check in the design process, and while the urgency is different, efficient use of time is important for making and reviewing drawings much less learning the latest software.

But architects can also be the ones designing spaces and tools in which to work quickly amidst high intensity. Barshi, the researcher from NASA Ames mentioned above, also cites and learns from architecture explicitly. ${ }^{18} \mathrm{He}$ references Christopher Alexander, but could also learn from earlier tachyscopic studies that undergirded the ideas of gestalt and its translations to form. Barshi holds a PhD in linguistics and draws on Gregory Bateson in his search for "a sound theoretical approach" to the abstraction, organization, and display of the "wealth of data" available to pilots. Presumably he needs an approach to form that works quickly and in conditions of potentially high emotion. It would also need to function in the low stimulus state of chronic monitoring of systems. One problem with automation (of flight, driving, or manufacturing) is that a human becomes disengaged when simply tasked with monitoring a mostly successful automata. Barshi suggests the need for a design of a more complex type of indicator that would help a pilot who quickly resumes attention to flying manually. ${ }^{19} \mathrm{He}$ suggests that interface design has done better with abstraction than with the structuring and integration of these displays. He proposes a model of hierarchical display of information, where indicators are not limited to "one-sensor, one-indicator" but which combine in complex patterns. He turns to medieval tile for models of complexity but I imagine architecture has more complex theories of form that would be of use.

Architecture is not new to the need to domesticate the emotions and machines that threaten to overrun the human. Historians such as Mark Wigley and Beatriz Colomina have argued that this is the core project of design. ${ }^{20}$ They have suggested that by definition, design is the making of peace at the painful interface between human body and machine task. 
John Harwood chronicled the way Eliot Noyes and other IBM designers have domesticated computers behind a smooth case. ${ }^{21}$ Branden Hookway has written eloquently on the consideration of the interface as a fluid, allowing the world war II era pilot to complete tasks of greater complexity and violence through the location of switches as well as the testing and selection of pilots. ${ }^{6}$ Further critical work in this area can be found in the journal Interface Critique which itself learns from Hookway's architectural history.

Rowe's understanding of perception was influenced by painting but also by psychologists and there is much overlap with the work of psychologist and art theorist Rudolph Arnheim who was interested in judging from what is seen quickly. Arnheim emphasized the value of experience, believing that art criticism should smell of the studio yet be a language apart. He felt perception did not proceed with single elements but from an understanding of expectation. His ideas are in line with Barshi's attempt to locate information where it would relate to other information needed at the same time. One wonders if Arnheim and Rowe's insights about balance, shape, line, and form would produce a richer understanding of the way to produce a complex indicator, with all modesty, I suggest it may be superior to medieval tiles? Clearly there is a lot more work to be done in this area.

And the work must be done with modesty. If formal empathy is wrong, and it may well be, and the horizontal line does not call to all subjects and invoke a state of calm, as Rudolph Schulze theorized in 1905, if the vertical does not move us to piety and uprightness of mood, then what? It is hard to tinker with the unspeakable and hard to teach the nonrepresentational. Affect shows a way out of arguments that form has such inherent qualities by setting design's role as mediator between sense and interpretation. As the field engages such work, it's key to remember the wartime history that led Rowe and Popper to object to attempts to try to move the masses through aesthetics. The role of design as modulator of intensity is a fraught with as many, if slower, social responsibilities in comparison to piloting.

\section{CONCLUSION}

The preceding exploration of what the two disciplines might offer to the psychology of occupying space could yield some practical solutions. It could also serve as a means of thinking about education and confronting the problem of including empathy, affect, accident in architecture pedagogy in a way that is more accessible than hoping students will intuitively "get it." Nigel Thrift speaks of one of the values of nonrepresentational theory as helping to push solidarity, to put handles on experience so that it can be discussed. A greater, and historically engaged, understanding of the differences between stimulus, emotion, and cognition would blend critical theory and social science to produce a far richer understanding of the role of representation and non-representation. As some

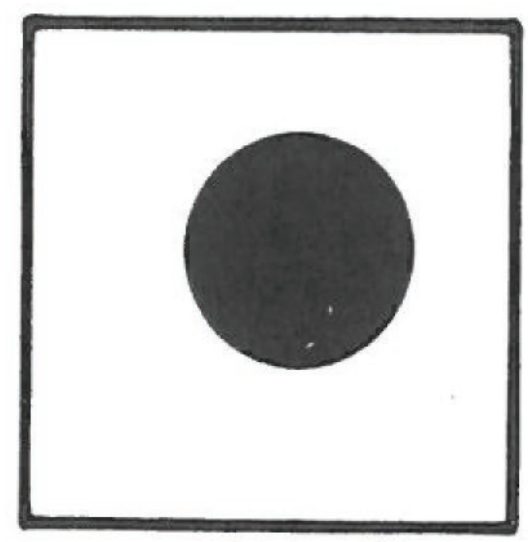

\section{Figure I}

Figure 4. An illustration of Arnheim's theory of balance, in this case the sudden perception that an element is not centered, due to experience that most of the time, it is. Rudolph Arnheim, Art and Visual Perception, A Psychology of the Creative Eye, (Berkeley: University of California Press 1974, c.1954), 10.

in our field are tempted to gestate naive ideas about virtual reality or other simulations that are very high in intensity and potentially very high in emotion (somehow thinking they are not in fact just as much of a representation as drawing), I think we need an antidote via theory. The lessons of affect and perception alter our alternatively inchoate and reductive understandings of "environmental psychology" such that architectural design can learn from "abnormal situation management" or guidelines for graphics that minimize emotional impact for those attempting to design wayfinding in hospitals, train stations, airports and cities.

In my reading, Banham was concerned about the dangers of having architecture remain as a black box. Yet architecture's core can contribute ideas uniquely able to rebalance all the "writing disciplines" of the humanities as well as all militarism of engineering. If architects were able to think and communicate with each other with clarity even about affect then our contribution to society, and to education would be impressive. Resistance to prevailing forces of consumerism and automatism, while we may welcome their benefits, will require criticality, reflection, and speaking to each other of our positions. It may also at times require us to engage with affect and other avowedly unsayable, nonrepresentational dimensions of experience: all those things that get cut out of a functionalized world where economics can be applied to all dimensions of life. For the black box was not only Banham's but also B.F. Skinner's and to avoid all the humanistic richness of psyche is to miss the point of humanity entirely. For ultimately humans exceed that animality, for better or worse, and we are able to design machines that fly, as well as machines that kill. 


\section{ENDNOTES}

1 Reyner Banham, "A Black Box: The Secret Profession of Architecture" in A Critic Writes: Essays by Reyner Banham, eds., Reyner Banham, Mary Banham, and Peter Hall (Berkeley: University of California Press, 2007), 292-299.

2 Adnan Morshed, "The Cultural Politics of Aerial Vision: Le Corbusier in Brazil (1929)," Journal of Architectural Education 55, no. 4 (May 1, 2002): 201-10.

3 Enrique Gualberto Ramirez, "Airs of Modernity 1881-1914," Ph.D. diss., Princeton University, 2013.

4 Sketches of Frank Gehry, directed by Sydney Pollack (Culver City, CA: Sony Pictures Home Entertainment, 2006), DVD.

5 Neil M. Denari, Gyroscopic Horizons (New York: Princeton Architectural Press, 1999).

6 Peter Galison, "The Ontology of the Enemy: Norbert Wiener and the Cybernetic Vision," Critical Inquiry 21, no. 1 (1994): 228-66; Brandon Hookway, "Cockpit" in Cold War Hothouses: Inventing Postwar Culture, From Cockpit to Playboy, eds., Beatriz Colomina, Annmarie Brennan, and Jeannie Kim (New York: Princeton Architectural Press, 2004), 22-54.

7 Brian Massumi, "The Autonomy of Affect," Cultural Critique 31 (Autumn 1995): 84.

8 Massumi, 86.

9 Zeynep Çelik Alexander, Kinaesthetic Knowing, Aesthetics, Epistemology, Modern Design (Chicago: University of Chicago Press, 2017), 23.

10 Sanford Kwinter, "Flying the Bullet - Oder Wann Begann Die Zukunft = Flying the Bullet, or When Did the Future Begin?" Arch Plus 132 (1996): 71-75, 80-83.

11 Immanuel Barshi, "Pathways to Human-Centered Operating Principles" in Trained for Life: Human-Centered Approach to Safety, Ph.D. panel presented at Air Line Pilots Association Human Factors conference, Washington, D.C., May 31, 2018. http://www.alpa.org/en/news-and-events/meetings-training/ hft-conference-05-2018.

12 The Crowd Above Me, The Sky Below, directed by Bill Rice, Art Scholl documentary produced for television (1968)

13 See Joy Knoblauch, The Architecture of Good Behavior, Psychology and Modern Institutional Design in Postwar America (Forthcoming from the University of Pittsburgh Press).

14 Isadore Rosenfield, Hospitals: Integrated Design (New York: Reinhold, 1951), 43.

15 Zeynep Çelik Alexander, "Looking: Wöfflin's Comparative Vision” in Kinaesthetic Knowing, Aesthetics, Epistemology, Modern Design (Chicago: University of Chicago Press, 2017), 23; Colin Rowe and Robert Slutzky, "Transparency: Literal and Phenomenal" Perspecta 8 (1963): 45-54.

16 Atul Gawande, The Checklist Manifesto: How to Get Things Right (New York, NY Picador, 2011).

17 Kuan-Ting Ho "Taking Note: A Design Solution for Physician Documentation to Balance the Benefits of Handwritten Notes and Electronic Health Records," Master of Design thesis, University of Michigan, Spring 2017.

18 Immanuel Barshi et al., "Using Medieval Architecture as Inspiration for Display Design: Parameter Interrelationships and Organizational Structure," Proceedings of the Human Factors and Ergonomics Society Annual Meeting 56, no. 1 (Santa Monica, CA: Human Factors and Ergonomics Society, 2012), 1799-1803.

19 Nicholas G. Carr, "On Autopilot" and "White Collar Computer" in The Glass Cage: How Our Computers Are Changing Us (New York: W. W. Norton \& Company, 2015), 43-63, 93-124.

20 Beatriz Colomina and Mark Wigley, Are We Human?: Notes on an Archaeology of Design (Zurich: Lars Müller Publishers, 2016).

21 John Harwood, The Interface: IBM and the Transformation of Corporate Design, 1945/1976 (Minneapolis, MN: University of Minnesota Press, 2011).

22 Branden Hookway, Interface (Cambridge, MA: The MIT Press, 2014). 